\title{
Geopolítica de las emociones en prácticas educativas de territorios de posconflicto. Estudio comparativo entre México, Guatemala y
}

\section{Colombia*}

\section{Geopolitics of Emotions in Educational Practices in Post-Conflict Territories. Comparative study between Mexico, Guatemala and Colombia}

\author{
Paula Andrea Orozco Pineda** \\ Corporación Universitaria Minuto de Dios (Uniminuto), \\ Vicerrectoría Regional Orinoquía, Colombia \\ https://orcid.org/0000-0002-0515-2914 \\ Edgar Oswaldo Pineda Martínez ${ }^{* * *}$ \\ Universidad Santo Tomás, Villavicencio, Colombia \\ https://orcid.org/0000-0001-6738-0237
}

Artículo de reflexión

Fecha de recepción: 16 de enero de 2020

Fecha de aceptación: 15 de abril de 2020

Artículo de reflexión producto del proyecto de investigación Pedagogía de las emociones para la construcción de paz en territorios de posconflicto, Colciencias, contrato 439 de 2017.

** Doctoranda en Educación, magíster en Educación con acentuación en Desarrollo Cognitivo y licenciada en Lenguas Modernas. Coordinadora de la Unidad de Transversales de la Corporación Universitaria Minuto de Dios (Uniminuto), Vicerrectoría Regional Orinoquía, Colombia. Miembro del colectivo de Educación para la Paz. Correo electrónico: paulaorozpi@gmail.com

*** Doctor en Ciencias Sociales (Humanidades y Sociedad Digital), doctor en Educación, magíster en Neuropsicología y licenciado en Filosofía. Docente de la Universidad Santo Tomás de Villavicencio, Colombia. Líder del Grupo de Investigación ABA y miembro del colectivo de Educación para la Paz. Correo electrónico: edgarpineda@usantotomas.edu.co 


\section{Para citar este artículo}

Orozco Pineda, P. A, y Pineda Martínez, E. O. (2020). Geopolítica de las emociones en prácticas educativas de territorios de posconflicto. Estudio comparativo entre México, Guatemala y Colombia. Campos en Ciencias Sociales, 8(2), 369-398. DoI: https://doi.org/10.15332/25006681/6023

\section{RESUMEN}

En este artículo se realiza una reflexión sobre el papel de las emociones en la permanencia del conflicto armado y en la construcción de paz desde la escuela. En este sentido, se exploran los conceptos de emociones politicas, geopolitica y conflicto armado; después, se hace referencia al contexto y a las alternativas pedagógicas ideadas por las comunidades en territorios de posconflicto, con el fin de promover una educación para la paz. El artículo busca presentar comprensiones sobre el lugar de las emociones en los procesos formativos orientados a la cultura de paz en zonas afectadas por el conflicto armado y social; para tal fin, se analizaron y compararon experiencias educativas ubicadas territorialmente en Chiapas (México), Quiché (Guatemala) y Meta (Colombia). Esto con el objetivo de establecer una geopolítica de las emociones proclive a la construcción de paz desde la educación.

Palabras claves: conflicto armado, emociones, escuela, geopolítica, paz, educación para la paz.

\section{Abstract}

This article reflects on the role of emotions in the continuance of armed conflict and in peacebuilding from school. In this vein, the concepts of political emotions, geopolitics, and armed conflict are explored; then, reference is made to the context and pedagogical alternatives devised by communities in post-conflict territories in order to promote education for peace. This article seeks to present insights into the place of emotions in educational processes aimed at the culture of peace in areas affected by armed and social conflict; to this end, educational experiences located territorially in Chiapas (Mexico), Quiché (Guatemala), and 
Meta (Colombia) were analyzed and compared, so as to establish a geopolitics of emotions conducive to peace-building from education.

Keywords: armed conflict, emotions, school, geopolitics, peace, peace education.

\section{INTRODUCCIÓN}

La pedagogía de las emociones para la paz (Quintero, Sánchez, Mateus, Álvarez y Cortes, 2016) se interesa por conocer las emociones que mejoran o deterioran los vínculos y valoraciones con los otros en el escenario de la escuela. Para esto, Quintero, Oviedo, Cuellar y Pineda (2017) reconocen que las emociones poseen un carácter comunicativo y promueven juicios, valoraciones, acciones y actitudes que favorecen o no a una cultura de paz. Para ello, (Quintero et al., 2017) consideran importante fortalecer una pedagogía de las emociones activa a la construcción de paz a partir del conocimiento y comprensión de las emociones que impulsan o desestimulan tanto las violencias como la cultura de paz. Para esto se requiere valorar los saberes y prácticas de los docentes en asuntos de formación de ciudadanía y cultura de paz de manera situada y contextual.

En este sentido, se desarrolló una investigación con enfoque mixto o cualimétrico que buscó, desde una naturaleza interpretativa-comprensiva, dar cuenta de las tramas narrativas de las emociones vinculadas a la cultura de paz, así como de las experiencias, saberes y prácticas educativas ubicadas en Chiapas (México), Quiche (Guatemala) y Meta (Colombia). Esto con el fin de comprender cómo las emociones morales y políticas permiten, en su aspecto proclive, conocer afectaciones, prevenir las violencias, impactar procesos de educación para la paz e incidir en la política pública y en agendas locales; o, por el contrario, generar agravios morales, romper vínculos y generar mayores violencias en y desde la escuela.

\section{EMOCIONES Y COMPORTAMIENTO HUMANO}

Toda acción humana esta generada, mediada o impulsada por emociones (Hume, 1757). Estas hacen referencia a afectaciones humanas que se desarrollan ante 
situaciones determinadas y configuran experiencias individuales y colectivas en las personas (Quintero y Mateus, 2014). Asimismo, en las emociones están implicadas prácticas morales y políticas que disponen una posición especial en las formas de ser y estar en un contexto. De esta manera, las emociones morales y políticas están presentes en el acto educativo como un ejercicio político y social de las comunidades. Por tal razón, es importante develar las emociones presentes en las narrativas de miembros de la comunidad educativa que han vivenciado experiencias territoriales de conflicto armado y de construcción de paz, con el fin de comprender las acciones cotidianas de la escuela que configuran comportamientos sociales a largo plazo.

Atendiendo a lo expuesto, es importante identificar las emociones generadas por la comunidad educativa que son proclives o declives a aportar en la construcción de una cultura de paz. De esta forma, se asume que las emociones presentes acerca de la guerra y la paz, en su naturaleza pública, contienen creencias y juicios, pero también comportan un carácter comunicativo y vinculante. Esto permite conocer los modos de afectación del conflicto en los territorios y dar cuenta de las formas de legitimación del mal, la cooptación de aspiraciones sociales y la fragilidad de la vida pública que se expresan y evidencian desde emociones paralizantes, como el miedo o la vergüenza. Según Quintero y colaboradores (2017), dichas emociones establecen unas retóricas de guerra basadas en discursos de justificación y legitimación de hechos atroces, horrorosos y de barbarie entre personas.

Sin embargo, las emociones también son capaces de gestionar acciones propositivas que se enmarcan y se manifiestan a través de narrativas aspiracionales, y que activan emociones como la indignación y la compasión, las cuales están orientadas a reconocer los sufrimientos vividos por los congéneres, a la promoción de acciones colectivas de resistencia y de restablecimiento de derechos. Dichas resistencias son generadas desde las emociones propensas a entender la fragilidad como capacidad humana para el anunciamiento y la filiación a reexistencias basadas en la paz, la solidaridad, el amor y el respeto. Quintero y colaboradores (2017) han denominado este tipo de emociones poéticas de la paz, las cuales centran acciones concretas de restablecimiento de vínculos, de agenciamiento y de reconocimientos para la construcción de paces intersubjetivas, colectivas y territoriales. 
Finalmente, es importante comprender también cómo en las tramas narrativas se hacen presentes situaciones que llevan a la insensibilidad o indolencia moral y política ante hechos de crueldad. Esto daría cuenta del mal público de la indiferencia; es decir, una performatividad del silencio cómplice que subyace a hechos de ignominia, abandono y desprotección. Estas emociones presentes dibujan una suerte de apatía y dejación ante el mal, debido a las diferencias sociales, políticas y étnicas que marcan un diferenciamiento absurdo y unas prácticas de indolencia moral en una sociedad. Quintero y Sánchez (2016) lo han denominado altericidios.

En este sentido, el presente artículo se centra en evidenciar los procesos de tres países que han vivido situaciones de conflicto y posconflicto. Esto con el fin de construir una geopolítica de las emociones presentes en los miembros de instituciones educativas que han vivenciado el conflicto armado y social, y a su vez han erigido y desarrollado iniciativas de construcción de paz territorial. El artículo parte de reconocer el papel vinculador de las emociones en la permanencia del conflicto armado y en la construcción de paces desde los procesos de formación y de reconocimiento del otro en la escuela. Por tal razón, el proyecto busca identificar las creencias, juicios y valoraciones que tienen los miembros de la comunidad educativa acerca de patrones de reconocimiento territorial en las dimensiones emocional, jurídica y social a través de narrativas docentes.

Atendiendo a lo expuesto, se evidencian los resultados y hallazgos que surgen de haberse propuesto los siguientes problemas: ¿de qué manera una pedagogía de las emociones aporta en la construcción de una cultura de paz en territorios de posconflicto?, ¿cuáles son las emociones de la comunidad educativa en territorios de posconflicto que contribuyen en la construcción de un enfoque pedagógico de las emociones para fomentar la cultura de paz?

\section{EMOCIONES EN EL CONFLICTO ARMADO Y SOCIAL}

Las emociones expresadas en tramas narrativas de los miembros de una comunidad educativa son evidenciadas a través de sus saberes y prácticas. Esto da lugar a tres tipos de tramas, que según Quintero y Mateus (2014), se identifican como retóricas 
de la guerra, poéticas de la paz y performatividad del silencio cómplice, las cuales se manifiestan en emociones que afectan los procesos educativos y el desarrollo normal de la vida escolar. En este sentido, estos tres tipos de tramas narrativas en contextos de guerra y en escenarios de construcción de paz — como en el que están inmersas las experiencias de Chiapas en México, Quiché en Guatemala y Meta en Colombiapermiten conocer los significados que tiene vivir juntos en la escuela y en los procesos de aprendizaje. Además, permiten identificar las violencias por afectación del conflicto armado en los contextos educativos y en la vida de los ciudadanos, los cuales han dado lugar a violencias armadas, así como a diversos modos de menosprecio (maltrato, desposesión e injuria) y humillación.

De igual manera, estas tramas narrativas permiten dar cuenta de aquellos procesos de aprendizaje de larga duración que han sido instalados en nuestros comportamientos y emociones, los cuales activan ideologías, estigmas, estereotipos y prejuicios que precarizan el entramado escolar, la vida ciudadana y la cultura de paz (Elías, 2012). Ahora, estas tramas narrativas docentes — que evidencian una adopción pedagógica a través de la cultura y educación, en su mayoría - presentan categorías relacionadas con memoria, justicia, verdad, perdón y reparación, entre otros, que aportarían en la construcción de paces territoriales.

En este sentido, se encuentra cómo se han creado unos sistemas complejos de organización en estos territorios afectados por el conflicto armado y social, en los cuales se encuentran actores, temporalidades y espacialidades, así como modos de humillación y menosprecio en lo moral, jurídico y social. Con ello, se ha instaurado el miedo y el terror como arma para hacer duradera e intensa la guerra y el conflicto social. Generar miedo ha sido una de las lógicas establecidas históricamente en estos territorios, donde, además, se evidencia poca presencia del Estado. Esto ha llevado a que los grupos armados e ilegales impongan un sistema normativo, en el que han predominado enfrentamientos por el dominio del territorio, pues algunas regiones son corredores estratégicos (tráfico de armas, cultivos ilícitos, entre otros).

Es preciso recordar que en estos territorios hay una geopolítica de las emociones asociadas con el terror, la humillación, la vergüenza, el asco y la repugnancia. 
Esta geopolítica permite dar cuenta de las emociones utilizadas para promover desplazamientos, secuestros, masacres y demás formas de violencia, en las que ha predominado la crueldad humana y que han dado lugar a unas tramas narrativas del mal. Estas situaciones se ven reflejadas en el territorio del departamento del Meta, Colombia, donde se establecieron los bloques de las denominadas Autodefensas Unidas de Colombia (AUC), a cargo de alias Martin llanos y alias Miguel Arroyave, quienes se disputaron violentamente zonas y territorios del departamento, con el fin de tomar el control de corredores y rutas estrategias para el desarrollo de la actividad del narcotráfico. En el transcurrir del enfrentamiento, en el departamento se cometieron las masacres de Mapiripán, en julio de 1997, y Puerto Alvira, en mayo de 1998. Estos hechos generaron dolorosas secuelas en las víctimas, en sus familiares y en el tejido social de la población.

Así mismo, enclaves territoriales como el Páramo de Sumapaz, la región de la Macarena y los corredores naturales que posee el departamento del Meta hacia las cuencas de los ríos Orinoco y Amazonas, le permitió a las guerrillas de las Fuerzas Armadas Revolucionarias de Colombia (Farc-EP) entender la región del Meta como un territorio estratégico para el comercio de estupefacientes y para replegar sus tropas tras escaladas terroristas hacia la población civil y la infraestructura del Estado. Esto generó dolor, presión social y miedo en los habitantes de los municipios que tenían influencia en los territorios ocupados por las Farc-EP.

En cuanto a población desplazada, para el departamento del Meta, según la Defensoría del Pueblo (2012), la cifra es de 130324 personas entre 1997 y 2011, así como 2934 muertes en combate entre 1998 y 2009. Las anteriores cifras alcanzaron para que el departamento del Meta, en el año 2004, obtuviera el segundo lugar en afectación civil por minas antipersona después del departamento de Antioquia (Alto Comisionado de las Naciones Unidas para los Refugiados [Acnur], 2016). Cabe resaltar que los mayores involucrados en relación con el conflicto interno fueron las AUC, razón por la que muchos investigadores explican el carácter más sangriento y despiadado en comparación a las muertes perpetradas por las Farc-EP (Acnur, 2016). 
Lo anterior propone una geopolítica del conflicto armado y social bastante particular en el departamento del Meta, viéndose afectada la totalidad de los municipios y teniendo presencia de todos los grupos armados legales e ilegales; librando batallas y guerras militares y sociales; y generando una estela de emociones positivas y negativas que, irremediablemente, han afectado el estar y el ser de sus habitantes. Estas dinámicas heterogéneas - desarrolladas, a lo largo del tiempo y en la totalidad del territorio en el departamento del Meta - han creado una diversidad de actores, víctimas y acciones violentos, sociales y culturales. Por tal razón, es necesario hacer una síntesis de los actores y víctimas del conflicto armado en relación con sus continuidades y cambios asociados con su vínculo con el territorio. Esto con el fin de evitar la persistencia del problema, la irrupción y propagación de nuevas problemáticas, y establecer protecciones a la población que limiten las influencias y presiones tanto institucionales como marginales.

Por otra parte, se tiene la particularidad del estado de Chiapas en México, allí se han vivido alternadas etapas de guerra y paz. Desde 1521 se evidencian conflictos armados en el territorio, de mayoría indígena. En aquella época los invasores españoles iniciaron una avanzada para conquistar las tierras del pueblo chiapeno. Su primer intento de colonización fue un total fracaso, debido a la ferocidad para defender su territorio por parte de los guerreros chiapanecos. En 1522 el español Diego de Mazariegos logró vencer a la fierra resistencia chiapaneca y estableció la Villa Real de Chiapas. Pero, solo hasta 1523 Hernán Cortes emitió una declaración total de conquista, y se generó, por más de cuatro años, una batalla que los chiapanecos libraron a favor de su libertad.

Para 1712 se configuró una sublevación indígena en Chiapas. Sus pobladores sufrían ya de las desigualdades y vejámenes de la colonia. Aunque los españoles eran solamente el $2 \%$ de la población de Chiapas, acapararon todos los cargos políticos y religiosos, monopolizaron el comercio y esclavizaron al $92 \%$ de los indígenas, a quienes utilizaban en plantaciones o como cargadores. Usaban a los criollos, mulatos y negros (6\%) en puestos de servidumbre, donde todos eran esclavizados y humillados al tener que emplearse con vejámenes para cumplir con la tributación impuesta. 
Con este panorama y con el sincretismo con el que la religión católica actuaba con las poblaciones originarias, varios indígenas de la región de Chiapas llevaron a cabo la sublevación del ejército de la virgen (1712), la rebelión de Quisteil (1761) y la Guerra de Castas (1792). En 1869 se configuró la rebelión Chamula, la cual fue un conflicto militar que se desarrolló en Chiapas, México, entre indígenas tzeltales y chamulas contra el Gobierno del Estado, encabezado por José Pantaleón Domínguez. Ya en el siguiente siglo, un año después que estallara la Revolución Mexicana, en 1911 Chiapas se levantó en armas. Esta vez, no era una rebelión de los indígenas y campesinos, sino que era una contrarrevolución, que surgió para hacer frente a las exigencias hechas desde la Revolución Mexicana. Estaba liderada por hacendados, terratenientes y comerciantes ricos sancristobalenses, que se oponían a la facción de los carrancistas; esta contrarrevolución fue llamada Rebelión Mapachista.

Finalmente, en el siglo xx, el 1 de enero de 1994 tuvo efecto el levantamiento zapatista por el autodenominado Ejército Zapatista de Liberación Nacional (EZLN). Este movimiento indígena lucha por la dignidad y dignificación del trabajo, la tierra, la vivienda, la salud y la educación, en respuesta a un conflicto interno que, durante siglos, ha generado una estela de emociones basadas en el odio, la humillación y la discriminación, y que ha generado un espiral de violencias sociales, físicas y psicológicas. Estas han sido revertidas por prácticas comunitarias de emancipación centradas en acciones educativas y formativas que, desde el manejo y reconocimiento de las emociones basadas en el orgullo, la memoria y la identidad, pueden solventar las históricas injusticias, el racismo y la discriminación en el territorio, y hacia las personas y colectivos.

Así mismo, se encuentra la experiencia de Quiché en Guatemala, donde encontramos una estela de discriminación y humillación a pueblos indígenas de antigua data. Como en el caso de Chiapas, Quinché ha sido un territorio saqueado desde la colonización, donde sus habitantes fueron despojados y esclavizados, sometidos a vejámenes y humillaciones por su origen étnico. A partir de 1960 y hasta 1996 en la llamada Guerra Civil de Guatemala, Quinché y sus habitantes fueron escenario y víctimas de combates, despojo de tierras, violaciones y agravios morales, entre 
otras cosas, por la presencia de industrias extractivitas y grandes terratenientes que buscaban enriquecerse con la devastación del territorio.

Para 1975 se registró la presencia del Ejército Guerrillero de los Pobres en Quiché, llevando a intensificar el conflicto, sobre todo en la región petrolera de Ixcán. La consecuencia de esta guerra fue el recrudecimiento de las masacres. Se llegó a registrar, entre otras, las de Nebaj, Chajul, Ixcán, Chisec, Panzós, Uspantán y Río Negro; todas ellas en zonas aledañas a oleoductos, campos petroleros, proyectos de infraestructura del Gobierno y de procesos extractivos de madera, y construcción de hidroeléctricas. Muchas de estas masacres perpetradas por el Estado guatemalteco fueron justificadas por la presencia del Ejército Guerrillero de los Pobres y sus atentados a la infraestructura de la nación. Hacia 1979, el Gobierno guatemalteco, para contrarrestar el triunfo de la Revolución Sandinista en Nicaragua, inició la ofensiva llamada Tierra Arrasada en la zona de Quiché. Allí se dieron ataques constantes a la población civil, que derivaron en más masacres; se llegaron a registrar más de 65 hechos de barbarie en solo el departamento de Quiché. Estas masacres eran cometidas por el Estado, se realizaban con premeditación y se efectuaban al aire libre; todo con el fin de generar miedo y zozobra, y de esta manera controlar a la población.

Entre las humillaciones y despojos realizados estaban la destrucción de viviendas, torturas, enterramientos en fosas comunes que dejan cavar a las propias víctimas, bombardeos indiscriminados; todas estas acciones se justificaban con retóricas de guerra basadas en pacificaciones y luchas contrainsurgentes. Estas acciones generaban dolor, miedo, ira y desarraigo, ya que los pocos sobrevivientes se veían obligados a desplazarse. Según la Comisión para el Esclarecimiento Histórico (1999) en su caso n. ${ }^{\circ} 77$, cuatro de cada seis aldeas que sufrieron masacres quedaron completamente arrasadas. Además, la población desplazada tenía solamente dos opciones: concentrarse en las cabeceras municipales bajo control militar o huir a las montańas (Indígenas maya $\mathrm{K}^{\prime}$ iche'). Esta última opción era considerada como guerrillera, y se cercaban y bloqueaban sus caminos imposibilitando el acceso a salud y alimentación, sufriendo y muriendo en completo abandono y de hambre. 
Esta situación de agravio, humillación y despojo llevó a que representantes del pueblo K'iché se tomaran, en 1980, la Embajada de España en Guatemala. La reacción del Gobierno fue inmediata: se provocó un incendio en la habitación donde se habían refugiado las personas que estaban en la embajada. Todos murieron, a excepción del embajador y Gregorio Lujá Yoná, uno de los indígenas, quien luego fue raptado del hospital donde fue remitido y torturado hasta morir por el Gobierno. Entre los datos esclarecidos por la Comisión para el Esclarecimiento Histórico (1999), en el periodo entre 1981 y 1982, más de cuatrocientos pueblos y aldeas fueron arrasadas, y miles de guatemaltecos fueron asesinados; muchos pertenecían al departamento de Quiché. Los sobrevivientes fueron reclutados en ejércitos paramilitares (Patrullas de Autodefensa Civil) o reubicados en campos de concentración; unos pocos lograron huir a zonas selváticas del Quiché, excluyéndose de la sociedad.

Después, algunos indígenas guatemaltecos volvieron a las zonas pobladas, estableciéndose en comunidades de población resistente conformadas por civiles desarmados que sobrevivieron con economías precarias basadas en el cultivo para consumo de maíz y fríjoles. Esta situación incrementó los niveles de pobreza en el departamento, extendiéndose hasta el día de hoy y llegando en el 2014 a un 74.7 \% en pobreza, de los cuales, el $41.8 \%$ está en pobreza extrema. Todo lo anterior, es consecuencia de un ejercicio sistemático de miedo, odio, ira, asco y otras emociones generadas hacia el indígena, el guerrillero y el pobre. Esto permitió que en la región se concentraran, en alta medida, unas prácticas de silencio performativo cómplice, que posibilitó el genocidio a los pueblos k'iche' e Itxil.

Entonces, con el análisis historiográfico del departamento del Meta (Colombia), el estado de Chiapas (México) y el departamento de Quiché (Guatemala) se evidencia el sentido de las emociones políticas y morales, para comprender cómo las violencias asociadas con el conflicto interno han tenido implicaciones de diversa índole en estos territorios; entre otras, encontramos la erosión del tejido social, el desarraigo de las comunidades, la vulneración de derechos, y, en especial, la precarización de la vida de las personas y de los colectivos. Lo anterior, genera esferas de humillación y desprecio hacia sí mismos y hacia los otros (que en muchos casos es o son los que los agraden). 
Además, estos sentimientos morales y políticos generados por emociones infundadas, basadas en el miedo y la coacción, no solo se han concentrado en contextos sociopolíticos en los ámbitos regionales, locales, barriales y comunitarios, sino que han influenciado profundamente los contextos educativos. En este sentido, el contexto escolar en los territorios de Chiapas, Quiché y Meta experimentan las consecuencias del conflicto armado y social, tanto a nivel de infraestructura como a nivel de acceso, calidad y desarrollo del mismo proceso. Al respecto, se puede señalar que en estos territorios la violencia se ha ensañado con la educación, y es la responsable de que niños, niñas y jóvenes no accedan al sistema educativo formal y, además, no se les garantice el derecho a la educación por diversas causas asociadas con las violencias.

De esta manera, dentro de las causas asociadas con las violencias identificadas en estos territorios de conflicto se encuentra, de manera recurrente, la militarización de los espacios escolares. Dicha acción pone en riesgo a niños, niñas y jóvenes vulnerables a la incorporación a fuerzas armadas. En este sentido, se evidenció que en el departamento del Meta, Colombia, los niveles de pobreza y de inequidad social y económica producto del conflicto armado generaron un crecimiento en la deserción e inasistencia escolar, ya que los niños, niñas y jóvenes, al evidenciar las pocas oportunidades sociales, culturales y políticas en sus territorios, optaron por dedicarse al trabajo de campo. En otros momentos, las razones de deserción de las escuelas fueron que los grupos al margen de la ley se establecieron como alternativas de subsistencia y la esperanza de un mejor estilo de vida.

Para el caso de Chiapas, México, se evidenció que la más latente de las violencias asociadas con el contexto escolar fue el desplazamiento forzado. Este se presenta a partir del recrudecimiento de la violencia armada y el despojo territorial y de servicios básicos hacia pueblos indígenas en la zona. De esta manera, los habitantes de Chiapas (en especial indígenas) no podían acceder a derechos básicos —entre ellos, la ambientación y la salud-, y se vieron despojados de su hogar. Por ello, tuvieron que buscar alternativas (inciertas) de vida en otras partes de la región y el país. 
Las consecuencias del desplazamiento humano en Chiapas arrojan cifras alarmantes de afectación a las infancias, con más de 20000 personas desplazadas en el periodo de 2016 a 2019 (Comisión Mexicana de Defensa y Promoción de los Derechos Humanos [CMDPDH], 2019), en su mayoría familias indígenas, quienes ven cómo el desplazamiento permite el reclutamiento de niños y niñas desde los diez años de edad, los cuales son usados como combatientes y soldados para misiones de inteligencia, como suicidas y escudos humanos ante conflictos entre fuerzas paramilitares, Estado y el EzLN. De igual manera, el desplazamiento es una situación de violencia generalizada donde, además, se es víctimas de otro tipo de violencias conexas. Los niños, niñas y jóvenes en Chipas sufren de violencia sexual y física producto del desarraigo y la vulneración permanente de sus derechos políticos, económicos, sociales, culturales y humanos.

En el caso del Quiché, se señala la prevalencia de violencia física y sexual, que erosiona constantemente el tejido social. Estas violencias, que están afectando concretamente a mujeres, niños y niñas, son perpetradas por estructuras criminales patrocinadas por pandillas y grupos paramilitares que, en muchos casos, están asociados con empresas y multinacionales extractivitas que buscan desestabilizar la sociedad y las comunidades para continuar con sus políticas de despojo. Este escenario de hostilidad, intensificado en regiones rurales, ha usado a las instituciones educativas —ubicadas en los epicentros del conflicto- como espacios de adoctrinamiento e instrucción militar, que propician el reclutamiento forzado, el abuso sexual y la trata de personas en el mismo territorio escolar.

Así mismo, la falta de presencia del Estado con programas y proyectos que solucionen y aborden las necesidades básicas insatisfechas de la población de Quiché, en su mayoría indígena, permite que las pandillas y grupos paramilitares establezcan proyectos y códigos éticos que ahondan en las brechas excluyentes, antagónicas y conflictivas con herencia colonial y de discriminación étnica. Esto configura autoritarismos y vulneraciones morales y físicas en las escuelas, donde se encuentra alto consumo de estupefacientes, violencia sexual, acoso, intimidación y asesinatos. 
Bajo estas condiciones, las escuelas y las comunidades educativas del estado de Chiapas (México) y los departamentos de Quiché (Guatemala) y Meta (Colombia) se van involucrando gradualmente en la dinámica del conflicto armado y social de sus territorios, recreando modos de humillación y menosprecio que se viven tanto en el entorno escolar, de convivencia, como en el curricular (Pineda y Orozco, 2018). En este sentido, las escuelas saqueadas y despojadas, los maestros y maestras coaptados, asesinados, secuestrados o amenazados, los nińos, niñas y jóvenes aleccionados con las creencias de estos grupos y los currículos educativos estatales reproductores de indiferencia y complicidad, permiten el florecimiento de resentimientos, ira y odio fratricida, que incrementan la humillación, la injusticia y la desigualdad social.

Es preciso indicar que para el goce pleno del derecho a la educación en territorios que sufren o han sufrido el conflicto armado es necesario, entre otras cosas, contar con medidas y estrategias de protección y seguridad física, cognitiva y socioafectiva para todos los miembros de la comunidad educativa. Esto con el fin de garantizar una educación sin interrupciones, orientada a la construcción del conocimiento y la personalidad, así como el fomento de la cultura, el respeto y el cuidado del medio ambiente. En este sentido, la responsabilidad de los Estados de México, Colombia y Guatemala está en deuda con estos territorios, no solo por la ineficacia para restituir los derechos de las víctimas y sancionar a los ejecutores de actos atroces, sino por la poca evidencia encontrada en estos territorios que muestre acciones gubernamentales que favorezcan acciones para el cuidado, el desarrollo emocional, la construcción de patrones de reconocimiento y la ética de las virtudes.

Sin embargo, lo que sí se logró identificar fue una serie de acciones comunitarias y colectivas que, desde la sociedad civil de los territorios de Chiapas (México), Quiché (Guatemala) y Meta (Colombia), se han llevado a cabo para considerar a las escuelas no solo espacios de formación académica, sino centros de apoyo y protección a la población infantil y adolescente (Romero Medina, 2013). En estos agenciamientos ciudadanos y colectivos, se entiende el espacio físico de las escuelas como territorio de atención para las comunidades, siendo, en algunos casos, "el espacio que, en medio de la dureza del conflicto armado, les da seguridad" (Romero Medina, 2012 p. 65). Pero, para que esto suceda, es necesario reconocer los efectos del conflicto en la escuela mediante el trabajo en la superación de los hechos de violencia vividos, la 
reivindicación de derechos y la restauración de la dignidad de niños, niñas y jóvenes. Lo anterior permite que la población de niños, niñas y jóvenes continúe dentro del sistema educativo, disminuyendo así los riesgos emocionales y su desarrollo como persona, y separando a los establecimientos educativos de ser espacios de resguardo, confrontación o adoctrinamiento político de uno u otro bando.

Para tal fin, se identificaron experiencias en Chiapas (México) que versaban sobre la reivindicación del papel, la práctica y el saber pedagógico de maestros y maestras en zonas rurales de conflicto y posconflicto. Esta reavivación del papel del maestro como etnoeducador se configura como un proceso de recuperación de la memoria pedagógica de los maestros y maestras, de sus instituciones educativas y de sus contextos naturales. En este sentido, dentro de los mandatos que configuran la democracia zapatista se encuentran: el mandar obedeciendo, las decisiones colectivas, el respeto a la diferencia, el autogobierno y la autocrítica. Estos principios se evidencian en las escuelas autóctonas como espacios autónomos de descolonización, donde —independiente al sistema estatal de educación de México- se configura una escuela de reexistencias indígenas, acorde con los ritmos, pensamientos y cosmologías de esta población (González-Casanova, 2003).

La estructura del sistema educativo zapatista se divide en dos ciclos: el primero incluye las escuelas primarias, las cuales están ubicadas en los propios territorios de resistencia (EPRAZ); y el segundo ciclo corresponde a las escuelas secundarias que se ubican en los denominados caracoles ${ }^{1}$ (ESRAZ). Todas las escuelas están divididas por niveles, pero no se limitan a la edad de los estudiantes, sino que están diseñadas para que se ajusten a las necesidades de cada alumno. Esto permite que en las aulas convivan estudiantes de diferente edad y género, que se educan en armonía y respeto bajo el principio zapatista: nadie educa a nadie y nadie se educa solo.

Este sistema autónomo de educación está basado en lo rural, lo étnico y en la generación de saberes y conocimientos. Su eje está en aprender quiénes son y cuáles son sus memorias y relatos de la historia y el presente, y trabajan la colectividad y los

1 Los caracoles hacen referencia a los espacios liberados por el EZLN, donde se hace autogobierno y corresponden a cinco regiones autónomas en Chiapas. 
procesos de reconocimiento intersubjetivo. Así mismo, los procesos de aprendizaje y enseńanza se desarrollan en lengua indígena originaria; esto como elemento integrador de sus procesos de resistencia y reexistencia descolonizadora.

Ahora, en el departamento del Quiché, Guatemala, la experiencia identificada se sitúa en la educación terciaria, específicamente en la Universidad Ixil Allí encontramos una apuesta educativa desarrollada en los territorios del pueblo maya de los ixiles, quienes fueron víctimas de la represión militar y paramilitar en el estado de Quiché en Guatemala. Desde el 2011, la Universidad Ixil interpreta el campo y la sabiduría ancestral como los pilares de sus apuestas educativas. En este orden de ideas, esta universidad no posee currículos y pénsum estandarizados y homogenizados a las lógicas occidentales; en cambio, se manejan macrotemas estructurados por la misma comunidad, que responden a problemas y necesidades de los mismos territorios.

Su metodología está basada en una investigación-acción y una educación de servicio comunitario, donde el conocimiento se adquiere en el terreno y no en las aulas. Se busca que el estudiante se conecte con la realidad social de sus comunidades y, de esta manera, genere actuaciones concretas para el beneficio de estas. En la Universidad Ixil los estudiantes se especializan como técnicos en Desarrollo Rural Comunitario y sus graduados se comprometen a ser defensores y defensoras de su tierra, y posibilitadores para el buen vivir en sus comunidades. Al igual que en la experiencia de Chiapas, donde no existen los maestros sino los promotores, en la Universidad Ixil se encuentran los facilitadores, quienes se desplazan a las comunidades y trabajan académicamente en los bienes comunes (tierra, agua, aire y fuego) ${ }^{2}$.

Dentro de sus intereses, la Universidad Ixil plantea una educación basada en sus propias creencias, que respeta e integra la naturaleza como un bien común; enfatizado su proceso en la autoconfianza y el autorrespeto como camino del reconocimiento y la comunidad ante la individualidad. Su eje didáctico es el diálogo y la palabra como posibilitante de reflexiones y cambios desde la interculturalidad epistémica y la ontología plural. La Universidad Ixil es una apuesta por la lucha permanente

2 Los cuatro elementos sagrados de la Madre Naturaleza son: la tierra 'loq'ola tx'ava", el agua 'loq'ola a", el aire 'loq'ola Kaqiq" y el fuego 'loq'ola xamal'. 
por el reconocimiento que han liderado los pueblos indígenas en Guatemala; es una reivindicación de sus estilos de vida a través de realidades orgánicas, sociales y comunitarias bajo el concepto de xula, que es el acto de intercambiar, en este caso conocimiento y acción por el territorio. Entonces, la Universidad Ixil, es lo que Padilla (2002) manifestó: "el doble carácter de la educación indígena: reproducción y resistencia” (p. 41).

Los casos anteriores demuestran cómo la guerra ha impactado la educación, no solo desde daños de infraestructura, saneamiento básico o equipamiento escolar, sino que ha significado la pérdida de identidad de estudiantes y docentes hacia un proyecto educativo nacional, que permita reconocerse en una comunidad desde la solidaridad, el honor y la filiación. Sin embargo, nos demuestra que estas situaciones de despojo y guerra generan inestabilidad en el sistema y deficiencia en la continuidad de los procesos pedagógicos (Pineda y Orozco, 2018). Lo anterior, es asumido por las comunidades como una posibilidad de reivindicación ante el abandono institucional, lo que genera experiencias de educación autónomas que propendan por un desarrollo emocional, por encima del racional, para una integridad de la educación con lo comunitario.

Sin embargo, estas experiencias, que son valiosas como actos de resistencia y reexistencia, no pueden sobreponerse a los daños ocasionados por el conflicto en los territorios, los cuales generan constante miedo en la comunidad educativa. "El tener que vivir en la cotidianidad con la posibilidad inmediata de ser víctima de acciones violentas ha llevado a que los maestros hayan interiorizado el miedo como patrón de conducta" (Lizarralde, 2003 p. 3). Al respecto, los ataques de grupos armados a comunidades educativas, se refieren al abuso físico y psicológico, al reclutamiento forzado, al asesinato, a la tortura, al secuestro y al desplazamiento forzado. Muchas de estas situaciones han sido consideradas consecuencias marginales o aisladas del conflicto, por lo que no se ha dado la atención necesaria a esta problemática (Pineda y Orozco, 2018).

Estas acciones educativas de resistencia y reexistencia se enmarcan en lo que Quintero y colaboradores (2016) presentan como pedagogías de las emociones. Estas exponen acciones pedagógicas reparadoras y restauradoras de la memoria, y de las emociones reveladas en los momentos de conflictos vividos por las comunidades educativas en 
territorios de conflicto. Dichas acciones pedagógicas se centran en las entidades, narraciones y emociones promovidas por el conflicto que experimentó la comunidad educativa, la cual busca, a través de la educación, superar las graves afectaciones en el bienestar emocional de las personas que ven rotos los lazos comunitarios, minadas sus confianzas y la imposibilidad de reconocer en cercanos y lejanos, personas dispuestas a ayudarlos a superar las experiencias atroces.

En lo que respecta a estos territorios que han sufrido las consecuencias del conflicto armado (Chiapas, Quiché), se generan unos puntos de encuentro con las instituciones educativas del departamento del Meta (Colombia), las cuales entienden que desde la educación se pueden comprender situaciones que propician la violación sistemática de los derechos humanos, como lo son el desplazamiento forzado y las vidas precarias de los inmigrantes internos. En este sentido, desde las acciones educativas se debe comprender cómo la gran mayoría de población rural en el departamento del Meta ve el desplazamiento a grandes ciudades (Villavicencio o Bogotá) como el único camino para huir de la violencia armada y social de sus territorios. Buscan que con el traslado cesen las afectaciones de humillación; sin embrago, lo que se genera es una nueva situación de vulneración, que se alimenta de las características y consecuencias que trae el desarraigo.

Para lo anterior, es necesario que las instituciones educativas del Meta se enfoquen, tal y como hacen las Escuelas Zapatistas, en el reconocimiento de las características personales y sociales de niños y niñas en los territorios afectados por el conflicto. Esto con el fin de relacionarlas con una propuesta pedagógica basada en la reconstrucción de la persona en términos de identidad, desarrollo de la personalidad y superación de conflictos emocionales. Para esto, se debe centrar una experiencia educativa basada en la producción de narrativas o relatos del conflicto armado en Colombia - de manera oral, escrita y performativa - que pueda manifestar, entre otras cosas, que la guerra no es muda y sus tramas narrativas bélicas están basadas en emociones que suceden en el devenir de la vida ética y política, las cuales se nutren de discursos y retóricas de orden social, institucional y educativo para justificar la guerra, el horror y la humillación. Dichas tramas narrativas están, en primera medida, dirigidas a los sediciosos y perpetuadores de violencias, y a sus estrategias morales y jurídicas que justifican la guerra. 
En segundo lugar, una estrategia desde la pedagogía de las emociones posibilitará la construcción de narrativas y relatos orales, escritos y performativos que busquen hacer resistencia y provoquen reexistencias ante los hechos de despojo. En este caso, al igual que lo desarrollado por la Universidad Ixil (Guatemala), se busca expresar las emociones que surgen de la identidad, la filiación y las capacidades de resiliencia en los niños, niñas y jóvenes en territorios afectados. Por último, es necesario transitar a otras narrativas de corte transmedia y digital que permitan sobreponerse a silencios indolentes basados en indiferencias e insensibilidad moral y política por parte de personas que piensan ser lejanos (territorial y políticamente) a los hechos ocurridos en los territorios de conflicto.

Finalmente, vemos cómo los conflictos armados dejan en los territorios una estela de emociones producto de la guerra. Allí se encuentran el odio, el asco, la repugnancia, la vergüenza, entre otros, que trascienden a todos los asuntos de la vida política y ciudadanía, así como a los valores políticos y morales, la idea de nación, las identidades, la libertad, la pluralidad, la vulneración derechos, entre otros, que persisten en la ciudadanía aun después del cese de los actos bélicos. Por ende, es a través de la educación y de los procesos de formación que, como resistencias a las herencias del odio y del mal, se sobreponen, desde prácticas basadas en el poder de comunicar, expresar y otorgar sentidos y significados al vivir juntos, al vivir en comunidad y al respeto de los bienes comunes (naturaleza y territorio). En consecuencia, estas prácticas pedagógicas, basadas en narrativas, se tejen de emociones, pues son estas las que contribuyen a que los hechos surjan o no; otorgan atributos a los sujetos, circunstancias, interacciones; $y$, en especial, pueden develan el horror del mal y la crueldad, o los reconocimientos del amor y la solidaridad.

\section{APRENDIZAJES EMOCIONALES: ESTEREOTIPOS, ESTIGMAS Y PREJUICIOS FRENTE A RECONOCIMIENTOS, SOLIDARIDAD Y AFECTOS}

Atendiendo a las experiencias de educación analizadas (Chiapas, Quinché, Meta), se puede comprender que en los conflictos armados y sociales de larga duración — donde de manera sostenida sus habitantes son afectados por violencias — existe 
una permanencia de costumbres y emociones que determinan transformaciones históricas en el orden social y en el comportamiento de las personas y los sujetos. De esta manera, vemos cómo en Chiapas el problema racial y el despojo de tierras perduran hasta nuestros días, debido a la instalación de patrones de odio y asco, como el menosprecio a las culturas indígenas originarias. $\mathrm{O}$ en casos como en Quiché, el despojo y la ignominia son referentes de patrones constantes de humillación hacia el campesino, la naturaleza y el territorio rural. Ante esto, Elías (2012) orienta que los cambios en la conducta y la sensibilidad de los individuos (psicogénesis) son consecuencia de las transformaciones en los entramados sociales (sociogénesis).

Por tal razón, para que surjan verdaderos cambios en las personas y en la representación de sus emociones se deben generar procesos sostenidos, en los que se puedan modelar comportamientos basados en patrones de reconocimiento intersubjetivo (Honneth, 1999). Siguiendo a Elías (2012), se podría sostener que en los territorios del estudio (Chiapas, Quiché, Meta) las tensiones del entramado social han ido generando diferentes redes de interacción, las cuales inciden en la modelación de aparatos psíquicos propios colectivos e individuales, pues producen cambios en su conducta y sensibilidad. Más claramente, los cambios sociales transforman el comportamiento y el sistema emotivo de las personas, así como la imagen que tienen de sí mismos, de los otros y del territorio. Para Elías (2012) la reorganización de las redes de interacción genera cambios en las costumbres humanas como respuesta a los patrones de civilización o de comportamiento y sensibilidad establecidos en la sociedad.

Entonces, se evidencia que en Chiapas, las luchas por la dignidad del pueblo indígena, sus costumbres y sus cosmogonías logran moldear una forma de autogobierno como principios (zapatistas) claros, que se ejemplarizan y viven en todos los entramados colectivos, incluyendo el educativo. Estos nuevos comportamientos colectivos, a su vez, van moldeando las subjetividades y las formas individuales de percibirse, lo que genera patrones de reconocimiento basados en la filiación y la capacidad de reconocimiento. Con dichos cambios, las personas y colectivos en Chiapas han organizado sus conductas, de manera tal 
que se reconstruyen identidades diferenciadas, estables y regulares. No se trata de una homogenización o de una dominación cultural, se trata de la construcción de legados identitarios que les permite construir redes de interacción y establecer funciones en la colectividad.

Por su parte, en Quiché las luchas versan por la reivindicación del trabajo rural, demostrando un manejo sustentable y armónico del patrimonio de la naturaleza. Esta propuesta la llevan a cabo a través del Xula', como tradición ancestral de intercambio de saberes y conocimientos. Esta práctica comunitaria es de tal intensidad, que las personas se ven obligadas a controlar sus conductas y emociones individuales automáticamente, posibilitando de manera libre las de contenido colectivo y de responsabilidad conjunta. Elías (2012) denomina este proceso autodominación, el cual está presente en sociedades avanzadas y consiste en entender colectivamente las formas de ser, actuar y sentir, lo que lleva a que se disminuya la creación de instituciones y formas de coacción que los lleven a actuar atendiendo a los modos establecidos. La Universidad Ixil es una muestra de emancipación y descolonización del saber y el conocer en los procesos de socialización de territorios afectados por la violencia a través de la construcción de tejido social solidario y equitativo.

De esta forma, se entiende que los procesos de sedimentación, después de un conflicto armado, no significan algo estático e inamovible; precisamente, con estas experiencias se evidencia que los procesos de sedimentación en acciones y emociones promovidos por desplazamientos, despojos y humillaciones generan formas de resistencia basados en la reconstrucción emocional de los colectivos. En los territorios estudiados se encontraron sedimentaciones basadas en odio y la humillación como procesos de autocoacción; también se encontró lo que Elías (2012) llama monopolios estables de violencia física, instituciones orientadas a reprimir las emociones y modelar el comportamiento de los individuos.

Estas sedimentaciones, producto de las trayectorias de guerra y conflicto armado, tienen particularidades sociales y territoriales. De esta forma, el conflicto armado en 
Chiapas se ha caracterizado por un desbalance en el manejo de tierras y autonomía entre colonos blancos y población indígena, la cual históricamente ha resistido a la invisibilización y exterminio que esas clases blancas y colonas la han querido someter. Por otra parte, está el conflicto en Quiché, donde el exterminio racial se ha visto expuesto durante el conflicto y el posconflicto, generando resistencias que las comunidades indígenas han logrado desde la educación y la preservación de sus saberes. Finalmente, las trayectorias de guerra en Colombia se ven reflejadas en el departamento del Meta, donde la población campesina, los indígenas y las comunidades afro han sido víctimas de todo tipo de vejámenes, que han erosionado la convivencia y el reconocimiento entre pares.

De esta forma, entre otras trayectorias, la transformación de las costumbres y hábitos en los periodos de conquista y colonia, el periodo de independencia y cada uno de los momentos de atrocidad en los territorios analizados, se constituyen en escenarios sociales que trajeron consigo el moldeamiento de la conducta y sensibilidad de los individuos y sus comunidades. En este sentido, en sociedades marcadas por la violencia (México, Guatemala, Colombia), señala Elías (2012), los sujetos no están protegidos del asalto repentino ni de las agresiones físicas, lo cual conlleva al establecimiento de relaciones de amistad o enemistad en el entramado social. Sin embargo, expone el autor, los peligros en este tipo de sociedades no solo surgen de la ausencia de regulación de los sujetos, sino de la amenaza del exterior, lo que genera un miedo que permea el entramado social.

\section{SOBREPONERSE A LA INEQUIDAD Y EXCLUSIÓN SOCIAL DESDE LA PEDAGOGÍA DE LAS EMOCIONES}

Para Honneth (2009) las situaciones de inequidad y exclusión social — como aquellas que caracterizan a los territorios de Chiapas, Quiché y Meta - son el producto de la ausencia de reconocimiento de los ciudadanos. El reconocimiento exige más que solo la confirmación recíproca de capacidades y posibilidades de los individuos, también implica una reconciliación con el otro. Se trata de valorar la existencia de un sujeto 
distinto de mí, el cual posee necesidades, carencias y sufrimientos; en la medida en que soy capaz de valorar la importancia que tiene el otro como particular dentro de un conjunto de organizaciones e instituciones, comprendo su papel irremplazable en el transcurrir de mi propia existencia. Esta reconciliación con el otro también me permite conocer aspectos profundos de su propia identidad, lo que implica hacer valer y reconocer como legitimas las reivindicaciones que hace sobre su propio estar en el mundo (Honneth, 2009).

Por ello, entender los problemas de desigualdad no implica, solamente, propender por una distribución equitativa de bienes o acceder a servicios básicos, sino promover la dignidad humana y el respeto recíproco, lo cual parte de fortalecer emociones orientadas a la autoestima, la autovaloración y el autorreconocimiento. El desprecio o ausencia de reconocimiento se constituye, entonces, en el motor de los conflictos o luchas sociales, ya que los individuos se ven convocados a reestablecer la valoración y apreciación que tienen los otros respecto a él, pues inicia un proceso de concientización de los menosprecios y dańos que sufren en la vida comunitaria (reconocer la injusticia). Este enfrentamiento es de carácter intersubjetivo, cuya finalidad última es reclamar o exigir los principios que confirman la identidad individual y colectiva del individuo. De esta manera, las luchas sociales son la consecuencia de la confrontación de intereses materiales opuestos y están fundados en sentimientos morales y políticos vinculados con la injusticia e inequidad.

Honneth (2009) destaca que la vulneración constante de derechos no se sustenta en una visión redistributiva de los recursos, sino que pone de manifiesto la falta de consideración por los individuos y colectivos menos favorecidos. El lenguaje moral del sufrimiento — producto de hechos atroces como la guerra - tiende a revelar sentimientos que reflejan el desprecio y la humillación que rige nuestra sociedad. Este autor indica, siguiendo la propuesta hegeliana, que existen diferentes formas de confirmación práctica, a través de las cuales los individuos se reconocen valorados en el entorno social. Estas formas, denominadas patrones de reconocimiento, corresponden a distintas esferas de la vida comunitaria, en las que los sujetos entablan relaciones éticas orientadas a participar de las acciones y toma de decisiones que afectan la vida en comunidad. 
De esta forma, Honneth (2009) propone, entonces, tres formas (patrones) de reconocimiento recíproco: emocional, jurídico y social. Estas tres formas de reconocimiento (dedicación emocional, reconocimiento jurídico y adhesión solidaria) configuran un estadio o manera de interacción social, en la que el sujeto es reconocido por los agentes sociales como un ser independiente y diferenciado, y cuyas capacidades son invaluables para la vida colectiva de los pueblos. El reconocimiento emocional está representado por las relaciones primarias de afecto, amistad y amor, en las cuales se dan experiencias recíprocas de atención amorosa entre sujetos que se saben dependientes. Entonces, es a través del cuidado amoroso que se procura el bienestar del otro, satisfaciendo sus necesidades individuales. Lo anterior, hace que las personas se reconozcan como sujetos necesitados, que requieren compañía y acogida: un estar-junto-a-si-en-el-otro. Cuando se presenta una fractura en este patrón de reconocimiento, aparece el maltrato o agresión (forma de menosprecio) que corresponden a la vulneración o lesión física del otro, atentando contra su bienestar y desarrollo.

En este sentido, el impacto que ha tenido el conflicto armado en las instituciones educativas de los territorios de Chiapas, Quiché y Meta, ha mostrado la emergencia de esta forma de menosprecio - maltrato- en los espacios pedagógicos. Las narrativas de maestros y maestras ubicados en zonas de conflicto interno muestran cómo, a partir de las presiones de la guerra, se instala en las comunidades y en los entornos de aprendizaje un estado de miedo permanente, debido a las amenazas que realizan los actores armados sobre: 1) los niños, nińas y jóvenes para que se unan a la vida ilegal y el combate armado; y 2) los docentes, para difuminar sus ideas de resistencia y transformación social. Para tales fines, los actores armados involucrados en el conflicto utilizan estrategias como la tortura, el asesinato selectivo e, incluso, las masacres, lo que se constituyen en fuentes destructivas de la psique, el cuerpo y la vida de la población. Lo anterior, genera que los docentes vivan o sobrevivan con una constante incertidumbre sobre el futuro y sobre sus vidas (Pineda y Orozco, 2018).

Para esto, es de reconocer que las prácticas educativas de las escuelas zapatistas y de la Universidad Ixil se convierten en una ruptura de moldes hegemónicos de dominación y alineación educativa; son mecanismos de resistencia cultural que, 
apoyados en las emergencias de supervivencia, se convierten en modos de generación de reconocimientos a través de la educación. En este marco, las escuelas zapatistas y la Universidad Ixil desarrollan un tipo de pedagogía de las emociones. Esta enfatiza en el acervo de la indignación y la compasión ante hechos crueles, como detonante de sentimientos morales y políticos para la consolidación de colectivos activos que luchen por el reconocimien to de que somos frágiles y que debemos cultivar emociones que permitan un cuidado mutuo y una búsqueda del bien común. En palabras de Nussbaum (2012), las escuelas Zapatistas y la Universidad Ixil propenden desarrollar “[...] una educación que cultive la capacidad de apreciar el carácter humano, pleno e igual de cualquier otra persona” (p. 16).

Por otra parte, el segundo tipo de reconocimiento según Honneth (2009), corresponde al jurídico y está relacionado con el derecho y la responsabilidad. Este patrón de reconocimiento reconoce a todos los individuos sociales como portadores de derechos, pero también como sujetos de deber, lo que implica que sus acciones pueden ser objeto de legitimación o sanción en el marco de la vida social. Este tipo de reconocimiento se establece a través de la identificación recíproca con otros seres iguales y libres que gozan de los mismos derechos y requieren de la misma satisfacción de necesidades. Entonces, el reconocimiento jurídico abre un panorama amplio acerca de las posibilidades que tienen los ciudadanos de concretar y realizar sus libertades individuales, así como de gozar de los bienes y servicios que ofrecen los cuerpos políticos (Nussbaum, 2014).

De esta forma, la ausencia de reconocimiento jurídico trae como consecuencia la desposesión de derechos y la exclusión social (forma de menosprecio). En estas situaciones, las personas son humilladas ya que, dentro de la comunidad, no se les reconoce legalmente como sujetos de derechos. Por esta razón no se les asigna imputación o responsabilidad jurídica y moral; si se sustraen los derechos que ubican a un individuo en el mismo lugar de sus congéneres, no se le considera responsable en igual medida que otros miembros de la comunidad. Tampoco encuentran cumplimiento de sus pretensiones y la satisfacción de sus necesidades se ve relegada e imposible de reivindicarse legítimamente. 
En este sentido, las acciones armadas en los territorios de Chiapas, Quiché y Meta, en especial, en zonas donde se concentran instituciones educativas rurales, ha mostrado cómo la guerra sustrae el derecho a la educación que tienen los niños, niñas y jóvenes de dichas comunidades. Las escuelas han sido utilizadas por los actores armados, legales e ilegales, como cuarteles provisionales; algunas de ellas han sufrido ataques armados, sus estudiantes han sido secuestrados, desaparecidos o reclutados, y sus profesores han sido asesinados o amenazados. En términos del Derecho Internacional Humanitario, la escuela es un bien civil que debe estar por fuera del conflicto, garantizando que sus actores educativos participen de procesos formativos que contribuyan al desarrollo de capacidades y, con ello, a su bienestar en el marco de la dignidad y la calidad de vida.

La cercanía y sufrimiento que las comunidades de Chiapas y Quiché han tenido a lo largo del conflicto armado, han generado una conciencia de los hechos atroces, de horror y barbarie y, por ende, de las emociones que suscitaron tales hechos; en el caso particular de estos dos territorios, sería el despojo y la humillación que sufren por ser pueblos indígenas. Este panorama de despojo y humillación ha logrado que en estos territorios, a la vez, surjan retóricas de guerra (Quintero et al., 2017) y emerjan procesos pedagógicos de creatividad. Estos, al sobreponerse al miedo y al silencio, posibilitan poéticas de paz (Quintero, et al, 2017), que permiten generar emociones basadas en el amor, la alegría y la empatía, como esperanzas para superar el dolor de lo vivido e ir edificando una vida más digna y más buena.

Por último, se encuentra el patrón de reconocimiento de la valoración social o solidaridad, entendida como el objetivo ético de toda sociedad. Para llegar a este objetivo ético se requiere que las comunidades sean plurales y que los ciudadanos tengan una autorreferencia positiva acerca de su vinculación social; referencia que está mediada por el orgullo y el honor, como emociones que expresan nuestro arraigo en una identidad colectiva. Nuestra valoración positiva al pertenecer a un grupo promueve acciones en el marco de la solidaridad. A este modo de reconocimiento le corresponde, como formas de menosprecio, la indignidad y la injuria. En este caso, se presentan situaciones de degradación y humillación frente a las realizaciones y proyectos personales que tienen los sujetos. Se trata, entonces, de una desvalorización de los modos de vida individual y colectiva, lo que implica adoptar sistemas de 
valores que determinan ciertas convicciones y experiencias como menos válidas o que presentan insuficiencias, por lo que se les sustrae a los sujetos la posibilidad de atribuir valor social a sus capacidades y facultades.

Precisamente, el conflicto armado en los territorios de Chiapas y Quiché se constituye en una experiencia que expone la contingencia y fragilidad de los seres humanos, la cual privó a las comunidades y las personas de la posibilidad de realizar sus planes de vida, así como llevar una vida digna de ser vivida. En estos territorios, las acciones y fenómenos asociados con este mal crearon las condiciones necesarias para acrecentar los odios y, con ellos, el desprecio entre los individuos, particularmente, en los niños y niñas, que, como se ha observado, son las víctimas más frecuentes de estas situaciones de guerra y menosprecio.

Por tal razón, estas comunidades se han preocupado por desarrollar prácticas pedagógicas que indaguen por las emociones que permiten perpetuar o disminuir los impactos del conflicto armado en sus territorios. Entones, las escuelas zapatistas y la Universidad Ixil se convierten para el departamento del Meta en ejemplos alternativos de transformación y construcción de paz desde la educación. Así, la pregunta fundamental para las instituciones educativas del departamento del Meta, que en el proceso de posconflicto desempeñan un papel preponderante a través del desarrollo de la cátedra de paz, tiene que ver con: ¡cuáles fueron las emociones imperantes que permitieron perpetuar una larga historia de violencia en los territorios? Asimismo, es importante que las comunidades educativas del departamento del Meta - y cualquier territorio en posconflicto - se pregunten por el nivel de daño moral en sus colectivos, para de esta forma, identificar qué emociones se deben potencializar para trasformar situaciones horrorosas y de barbarie en acciones de construcción de paz desde la pedagogía de las emociones.

Finalmente, el análisis de tres realidades de los territorios de Chiapas, Quiché y Meta, los cuales que han vivido el conflicto y han desarrollado reexistencias, en los inestables momentos de posconflicto, evidencian el papel fundamental de las emociones, ya sea para la continuidad del conflicto o para su transformación. Estas emociones están, a su vez, presentes en las narrativas y relatos de las comunidades, 
colectivos y personas. El papel de la educación consiste, entonces, percibir e identificar las emociones para que, a partir de la creatividad, se logre formular estrategias que permitan generar agenciamientos y compromisos políticos para la construcción de paces territoriales.

En este sentido, la escuela se erige como el escenario idóneo para la transformación del conflicto y la generación de patrones de reconocimiento que superen los modos de menosprecio y humillación generados por el conflicto armado. Para esto, queda recoger las semillas sembradas por las escuelas zapatistas y la Universidad Itxil, donde el amor, la solidaridad y el reconocimiento son pilares fundamentales y se pueden sentar los procesos de perdón, reconciliación y memoria para la no repetición de hechos atroces en el departamento del Meta.

\section{REFERENCIAS}

Alto Comisionado de las Naciones Unidas para los Refugiados (Acnur). (2006). „Déjennos en paz! La población civil, victima del conflicto armado interno en Colombia. Recuperado de http://www.acnur.org/t3/fileadmin/scripts/doc.php?file=t3/fileadmin/Documentos/ Publicaciones/2008/6736

Comisión Mexicana de Defensa y Promoción de los Derechos Humanos (СмDPDH). (2019). Informe de desplazamiento interno forzado masivo. México: CMDPDH.

Comisión para el esclarecimiento histórico (Unops). (1999). Guatemala, memoria del silencio. Guatemala: Unops.

Elias, N. (2012). El proceso de la civilización: Investigaciones sociogenéticas y psicogenéticas. México: Fondo de Cultura Económica.

González Casanova, P. (2003). Los Caracoles zapatistas: Redes de resistencia y autonomia. Buenos Aires: cLACso. http://biblioteca.clacso.edu.ar/clacso/osal/20110221035814/2d1casanova.pdf 
Honneth, A. (2009). Critica del agravio moral. Patologías de la sociedad contemporánea. Buenos Aires: Fondo de Cultura Económica.

Hume, D. (1757). Disertación sobre las pasiones y otros ensayos morales. Madrid: Antropos, edición 1990.

Lizarralde, J. (2003). Maestros en zonas de conflicto. Revista Latinoamericana de Ciencias Sociales, Niñez y Juventud, (2) 1. Recuperado de http://biblioteca.clacso.edu.ar/ Colombia/alianza-cinde-umz/20131004012443/art.MauricioL..pdf

Nussbaum, M. (2014). Emociones politicas: ¿Por qué el amor es importante para la justicia? Barcelona: Paidós.

Nussbaum, M. (2012). Crear capacidades. Propuesta para el desarrollo humano. Barcelona: Paidós.

Padilla Arias, A. (2002). El doble carácter de la educación indígena: reproducción y resistencia. REencuentro. Análisis de Problemas Universitarios, (33). Recuperado de https://www.redalyc.org/articulo.oa?id=340/34003305

Pineda, E. y Orozco, P. (2018). El papel de la educación en un Estado Social de Derecho para la consolidación de un (as) paz (ces) sostenible(s) y duradera(s). En G. Eljach Pacheco, J. A. Escobar Solano, I. Muñoz Meneses y G. Niño Contreras (compiladores), Aportes Académicos para la Agenda Legislativa en Educación. Serie documentos estudios legislativos $n^{\circ} 5$. Centro de Altos Estudios Legislativo. Congreso de la República: Colombia. Recuperado de http://cael.senado.gov.co/cael/publicaciones/57-serie-5/file

Quintero Mejía, M. y Mateus Malaver, J. (2014). Sentimientos morales y políticos en la formación ciudadana en Colombia: atributos y estigmas. Folios, (39). Dor: https://doi.or g/10.17227/01234870.39folios 137.147

Quintero Mejía, M. y Sánchez, K. (2016). Emociones morales y políticas en el paradigma del mal: El (NO) lugar de la infancia. Investigación y Desarrollo, 2(24). DoI: http://dx.doi. org/10.14482/indes.24.2.8898 
Quintero Mejía, M., Oviedo, M., Cuellar, C y Pineda, E, (2017). Pedagogía de las emociones para la construcción de paz en territorios de postconflicto. Bogotá: Proyecto Colciencias, Contrato 439 de 2017.

Quintero Mejía, M., Sánchez, K., Mateus, J. y Cortes. R. A. (2016). Pedagogía de las Emociones para la Paz. Bogotá: Idep.

Romero Medina, F. (2013). Conflicto armado, Escuela, Derechos Humanos y DiH en Colombia. Análisis Político, 26(77), 57-84. Recuperado de https://revistas.unal.edu.co/index.php/anpol/article/view/44001/45251 